\title{
What happens in Norwegian epidemiological research on mental health? A contemporary perspective
}

\author{
Kristian Tambs \\ Division of Mental Health, Norwegian Institute of Public Health, Box 4404 Nydalen, NO-0403 Oslo, Norway \\ E-mail: kristian.tambs@fhi.no Telephone +47 21078223 \\ This is an open access article distributed under the Creative Commons Attribution Licence, which permits unrestricted use, distribution, and reproduction \\ in any medium, provided the original work is properly cited.
}

The late Prof. Odd Steffen Dalgard, a distinguished Norwegian psychiatric epidemiologist, thirteen years ago in Norsk Epidemiologi wrote the article «Psykiatrisk epidemiologi i Norge - et historisk tilbakeblikk i norsk epidemiologi» ("Psychiatric epidemiology in Norway - a glance back in history") (1). There he rather comprehensively described epidemiological research on mental health until around 1980 and, a little more selectively, what happened from then until the new century. He did not include genetic epidemiology. Rather than trying to repeat Dalgard's descriptions, I will delimit the description of old Norwegian psychiatric epidemiology to listing a few milestones and then, in a little more detail, try to give a picture of epidemiological research on mental health in Norway during the last two decennia. I will also pass on some results from genetic epidemiology on mental health, including some early research.

Psychiatric epidemiology has a long tradition in Norway. In fact, the major part of early psychiatric research in Norway can be categorized as epidemiology. The first systematic counting of mentally ill persons in Norway was conducted by Fredrik Holst in 1825 (2). Prof. Ørnulf Ødegaard's studies of mental illness among Norwegian immigrants in Minnesota around a century ago was subject to international attention (3). Ødegaard also in 1936 established The Central Registry for Hospitalizing of Mentally Ill Patients. The registry, which existed until 1989, included diagnoses of psychotic patients hospitalized at hospitals for mental illness in Norway and resulted in several studies on the importance of social background and demography, like gender and education (4) and occupation (5). Among other important research was the investigation of mental illness in a small fishing community in the very north of Norway (6). Nils Johan Lavik's (7) study from the early 1970s of mental health and illness among 2265 adolescents is also a milestone. Odd Steffen Dalgard conducted an interview study of 1010 persons living in a suburb of Oslo around 1985 and interviewed them 10 years later to study effects of changing neighborhood quality on mental health (8).

\section{A NEW ERA IN NORWEGIAN EPIDEMIOLOGY ON MENTAL HEALTH}

In Norway, epidemiology was quite suddenly brought to broader attention after "Health, Environment, and Life Conditions" (HEMIL) was appointed scientific priority by the Norwegian parliament's White Paper on research in 1985 and was started as a program in the Research Council of Norway (RCN) in 1986. Another program in the Research Council, the Program for Mental Health, strongly advocated for and later headed by Per Vaglum at the University of Oslo, had started in 1982. The Mental Health program was vital to Norwegian mental health research generally, and as a funding source of psychiatric epidemiology perhaps even more important than the HEMIL program. Another event important to mental health research was the Norwegian Broadcasting's TV campaign in 1992. In collaboration with the charitable organization Council of Mental Health, the national broadcasting company, NRK, raised around NOK 80 million for prevention, support and research related to mental health. The organization established in order to administer the money, "Norwegian Extra Foundation for Health and Rehabilitation", soon started to receive money regularly, earned by the governmental lottery "Extra" and yearly supports research on mental health with 10-20 million.

The new epidemiology groups that were growing from HEMIL were from the start almost totally dominated by somatic medicine. From the 25 dissertations financed by HEMIL, to my knowledge only one, by Inger Sandanger, was about mental health (9). The HEMIL Center at the Faculty of Psychology in Bergen produced some epidemiological research, but the center primarily focused on health behavior and prevention. A few years later, however, the enthusiasm for epidemiology started to spread to psychiatry, psychology and social sciences. Epidemiological research on mental disorders had until around this period, internationally as well as nationally, been a purely medical discipline and was called psychiatric epidemiology. Later psychiatric epidemiology has been outgrowing medicine and has become an interdisciplinary research branch. The term psychiatric epidemiology is no longer fully appropriate, instead I will propose the term mental health epidemiology (MHE).

The new interest for MHE resulted in a number of new research groups. In 1990 a new center was established, "Senter for sosialt nettverk og helse" [Center for Social Support and Health], employing around 20 researchers (10). The center was funded by and reporting to the Norwegian Directorate of Health, located at Ullevål University Hospital, and headed by Odd Steffen Dalgard. Of basic importance for the policy of the center was - as indicated by the name - the recog- 
nition of the importance of social network and support for mental health. The center was closed after five years but had by then contributed to the recruitment and training of new MHE researchers and produced some successful studies, among these the TOPP study, which is still active (11).

New funding sources and institutions can explain much of the new drive in mental health research during the nineties. A more overarching explanation is the increasing appreciation of the importance of mental health and illness, internationally and nationally. At least in Norway this enthusiasm for improving public mental health extended into the new century, resulting in "Escalation Plan for Mental Health". From 1999 to 2008 the government decided to spend NOK 24 billion extra on health, treatment, and prevention during the ten year period, and to increase the yearly costs by 4.2 billion from 1998 to 2008 . One action was to stimulate education and research on mental health. During this period the Norwegian Centre for Violence and Traumatic Stress Studies (NKVTS) was established (2004). The center has around 80 full or part time employees and describes its main tasks as "Research and development, as well as dissemination in the form of teaching, guidance and counselling." (12). THE Norwegian Institute of Public Health (NIPH) started to expand its research activity on mental health around 2000 and in 2006 established its new Division of Mental Health, which by 2010 had around 100 employees. Most of the research on mental health at the NIPH is epidemiology. In 1996 several research institutions were merged to one institution, NOVA (Norwegian Social Research), which today has approximately eighty full-time employees. NOVA specifies its key research areas as: Childhood and child welfare, Youth, Ageing and the life-course, Family, Social security and social assistance, Housing, Migration, Welfare state, and Health and welfare. Even if the scope is social science rather than mental health science, NOVA has produced important epidemiological research, especially on mental health in adolescents.

There are now four Regional Centres for Child and Youth Mental Health and Child Welfare (RBUP and RKBU), located in southern and eastern Norway, in the western areas, in central Norway and in northern Norway. The centers grew out of Norwegian child psychiatry and were founded during the 1990s. The centers engage in research, development, teaching and dissemination in the fields of child and adolescent mental health and child welfare and increasingly contribute to epidemiology on mental health in children and adolescents.

Besides the foundation of new institutions, the MHE research at the universities has expanded a lot. Certainly there has been two good decades for Norwegian epidemiological research on mental health. To examine the development of research production within MHE, a literature search was run in Web of Science. The combination of search terms was intended to hit epidemiology on mental health (see Appendix 1). The search was intentionally made rather narrow. It was meant primarily to hit results with mental health variables, including alcohol and drug problems, as end-points, not as predictors. Dementia, pain, and sleeping problems were not included. Inevitably, to some extent the choice of search terms is arbitrary. The technicalities of the searching procedure are described in Appendix 1.

The search results, shown in Figure 1, is everything but a precise measure of MHE research activity. They probably give a hunch of the total number of MHE publications in Norway during the last three decades but, due to the strict search criteria, strongly underestimate the number of what could possibly be categorized as MHE publications. It gives a good impression of the increase in publications, however. Numbers of yearly publications before 1990 are single digits. From then until around 2003 there was a steady increase up till around 70 publications a year. Since then and until 2013 the number has increased four-fold. The search was run when a large part of the 2014 publications were not yet registered.

\section{WHERE DOES THE MHE RESEARCH TAKE PLACE?}

It may also have some interest to quantify the MHE research activity in terms of distribution across various research institutions. The technical procedures for estimating the relative distribution of MHE publications across institutions are described in Appendix 2.

The relative distribution across research institutions is shown in Figure 2. It would take too long to report such a distribution specifically for different time periods. Braking down on publication years would also give limited information, since more than half of the publications are from 2009 or later. On the following pages are short descriptions of those research sites that altogether produce in the order of $90 \%$ of all MHE research in Norway.

Medical Faculty, UiO, including the university hospitals belonging to Oslo, according to this approximate estimation produces $37 \%$ of the MHE publications in Norway during the last three decades. Some of the publications are within molecular genetics, in which there are sometimes more than hundred co-authors. In the statistics shown in Figure 2 a co-authorship counts the same regardless of number of authors on a paper. Even if this publication count may slightly have favored the Medical Faculty in Oslo, it has undoubtedy been the most important MHE center in Norway and probably produced around one third of Norwegian MHE research. This research activity is shared by many units in the faculty. The hub of MHE research at the UiO has been the Ullevall group, built by Svein Friis and Stein Opjordsmoen Ilner during the 1990s and early 2000s. During the last years Ole Andreassen, Ingrid Melle, and Ingrid Agartz have been among the 


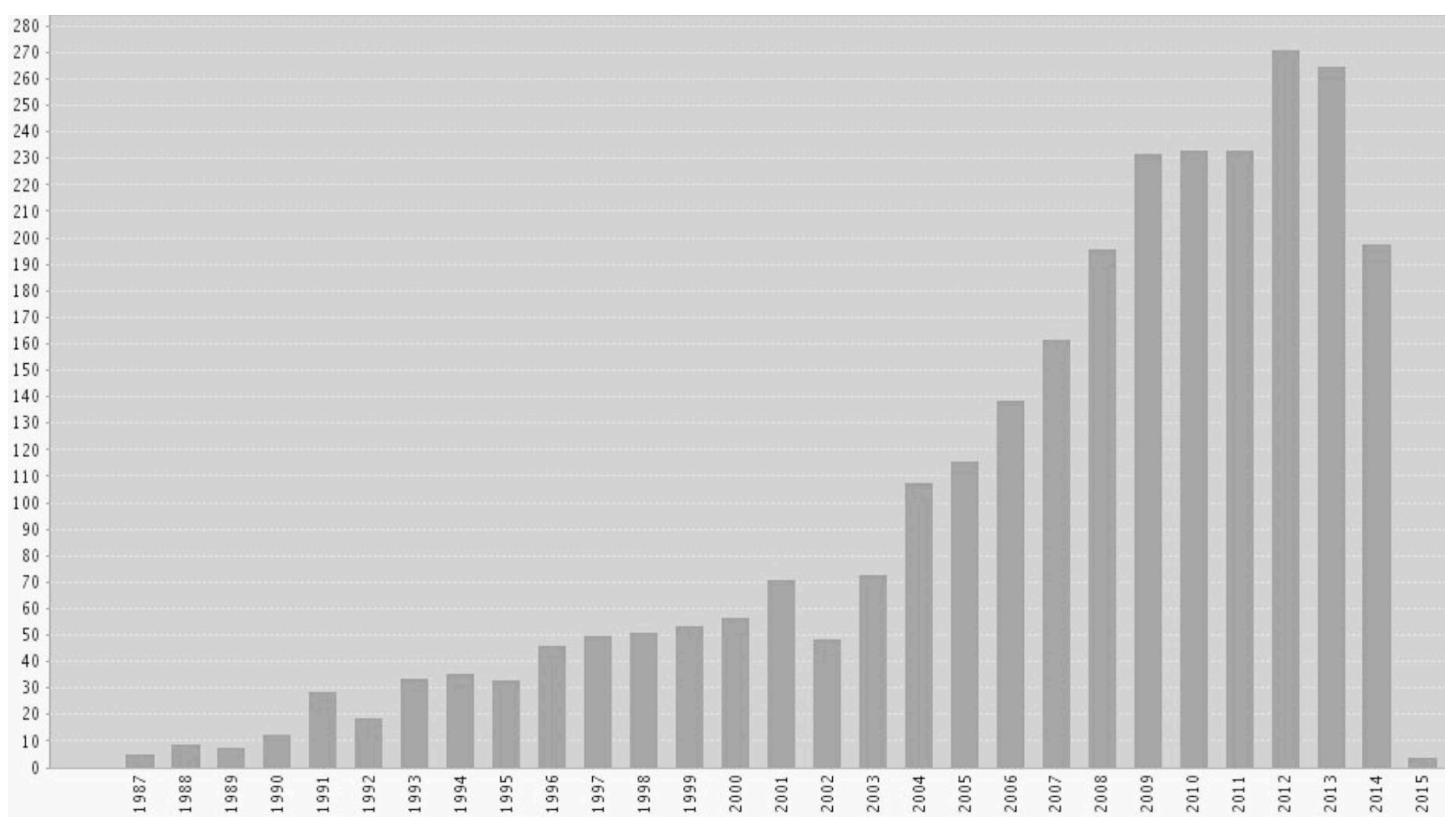

Figure 1. Peer-reviewed and indexed publications on mental health epidemiology in Norway.

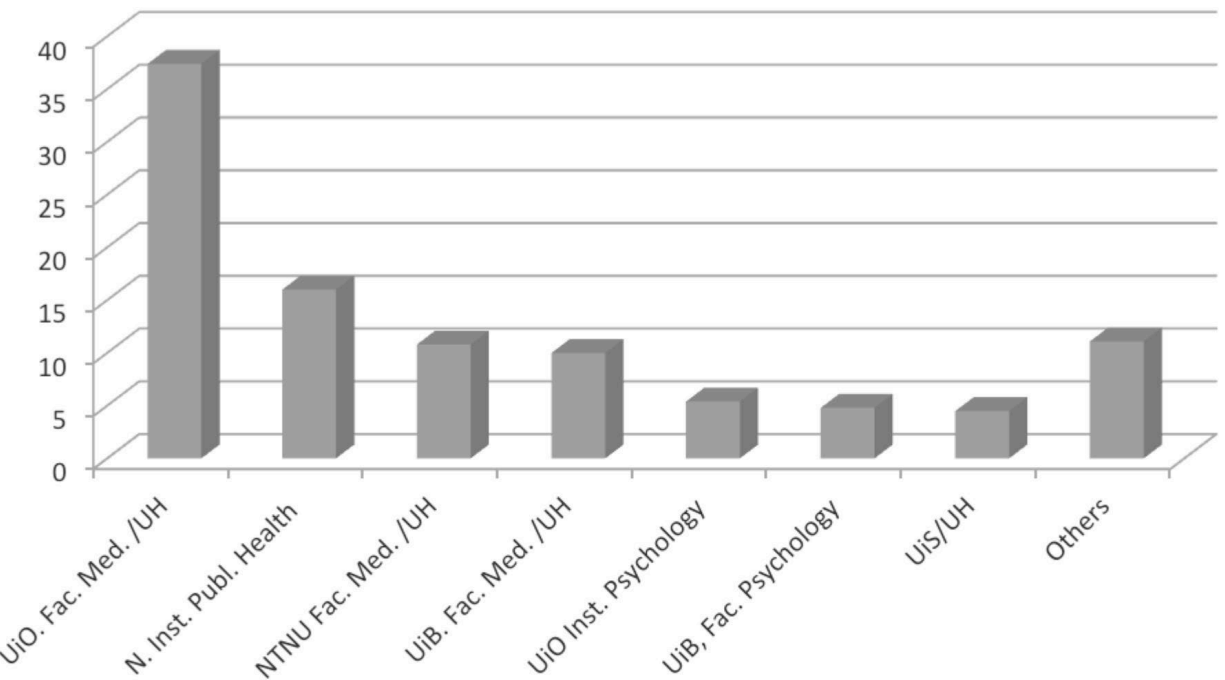

Figure 2. Distribution of epidemiological research on mental health in Norway. Estimated percentage of total number of publications.

most central researchers. A major focus for the Ullevål group has been long term outcome studies of representative psychosis patients. Recently a prioritized activity has been the population genetic studies of severe mental disorders.

After a recent reorganization, the vast majority of research on mental health, including $\mathrm{MHE}$, at the $\mathrm{UiO}$ is now gathered at the Institute of Clinical Medicine, with the following units:

- Clinic of Health Service Science and Psychiatry, Akershus University Hospital (7 employees).

- Clinic of Mental Health and Addiction is associated with Oslo University Hospital, and consists of five groups:

o Norwegian Centre for Addiction Research (SERAF) (40-50 employees). o National Centre for Suicide Research and Prevention (approximately 10).

o Unit Child and Adolescent Psychiatry (previously BUP) (approximately five).

○ Adult Psychiatry Unit, (approximately 20).

o A new center of excellence, NORMENT, is run in collaboration between the universities in Oslo and Bergen and is funded by the RCN. The Oslo part is headed by Ole A. Andreassen (approximately 30).

It may seem inappropriate to treat the large and heterogeneous body of MHE research at the Medical faculty in Oslo as a single unit. However, a number of reorganizations at the faculty make it difficult over a long period to locate all the publications correctly within the faculty. There are many important MHE 
publications from UiO (13-19). A few will be briefly presented later. Highly productive MHE researchers, meeting the criterion $20+$ hits on the literature search, are Ingrid Agartz, Ole A. Andreassen, Ingrid Melle, Alv A. Dahl, Srdjan Djurovic, Øyvind Ekeberg, Knut Engedal, Sophie Fosså, Einar Kringlen, Torbjørn Moum, Stein Opjordsmoen Ilner, Inger Sandanger, and Per Vaglum.

Norwegian Institute of Public Health (NIPH) was estimated to have contributed with $16 \%$ of the MHE publications in Norway during the last decades. MHE became a gradually more important part of the epidemiological research at NIPH from around 2000, resulting in a separate Department of Mental Health from 2006 with around 100 employees. NIPH hosts the Norwegian Mother and Child Cohort (MoBa) study. A substantial part of the MHE research on NIPH is based on data from this study. So far a large part of the MHE researchers on NIPH have studied moderately severe mental disorders and problems like symptoms of anxiety and depression. The institute is the national center for twin studies of mental disorders, in which both questionnaire data on symptom levels and interview data on specific disorders have been collected. Examples of important studies from NIPH are briefly described later (20-22). Highly productive MHE researchers $(20+$ hits) are (the late) Odd Steffen Dalgard, Jennifer Harris, Arnstein Mykletun, Ted Reichborn-Kjennerud, Børge Sivertsen, Kristian Tambs, and Simon Øverland.

The Medical Faculty at the Norwegian University of Science and Technology (NTNU) was estimated to contribute with $11 \%$ of the MHE in Norway. Two of the faculty's five departments, Department of Neuroscience (DN) and Department of Public Health and General Practice (DPHGP) [ISF] appear to produce $80-90 \%$ of the MHE publications at the faculty. The former includes the successful group of Headache Research, which publishes some MHE relevant research, but the most important contribution to MHE within DN comes from group of Psychiatric Disorders. The group has since long been strongly associated with psychiatric institutions in the Trøndelag area, especially Østmarka Hospital, where Karl G. Götestam for many years held a key role. During the last years Gunnar Morken has been among the leading MHE researchers in the psychiatry group and in NTNU generally.

DPHGP hosts the Nord-Trøndelag Health Study (HUNT), one of the most important epidemiological studies in Norway. There are no data on specific psychiatric diagnoses in HUNT, only on psychological well-being, general emotional distress, and symptoms of anxiety and depression, which is reflected by the general character of the outcome variables in most HUNT based MHE. It is also possible to link "harder" outcome data from registries to the HUNT data, for example suicide, as in a publication from NTNU shortly outlined later (23). Among researchers that have used mental health data from HUNT are Johan Håkon
Bjørngaard from DPHGP and Ottar Bjerkeset from DN. Main topics of MHE research in NTNU, Medical Faculty have been the epidemiology of anxiety, depression, sleep, and self-harm/suicide. Only one researcher at the faculty, Gunnar Morken, had more than 20 literature hits, whereas a lot had more than ten.

The Faculty of Medicine and Dentistry at the UiB. This faculty was estimated to produce around $10 \%$ of MHE publications in Norway. There is MHE activity on all four departments (Clinical Medicine, Biomedicine, Global Public Health and Primary Care), somewhat more on the clinical than on the other departments. A molecular genetic group, in which one of the key persons is Vidar Steen, has published a large number of results on genetic effects on mental disorders. Others of the researchers have based their research on data from the big population based studies like the Health study of Hordaland (HUSK) and HUNT. Papers from UiB (24-26) will be briefly described later. Highly productive MHE researchers are Bjørn Bjorvatn, Ole Bernt Fasmer, Jan Haavik, and Vidar Steen.

University of Stavanger (UiS) and Stavanger University Hospital produce somewhat around 8\% of Norwegian MHE research. Since UiS does not have a medical faculty, most of the MHE research appears to be spread on various clinical groups at the university hospital. The hospital has a very strong research group on Parkinson's disease (a publication from which will be shortly described later), The Norwegian Centre for Movement Disorders. A substantial part of the MHE from Stavanger is from this group and typically examines mental health outcomes in Parkinson patients (27). Another part of the MHE research has been conducted in the TIPS project (acronym for early detection and treatment of psychosis), in which Prof. Tor Kjetil Larsen has a key role. Highly productive MHE researchers are Dag Aarsland and Jan Petter Larsen.

The Department of Psychology at the UiO. The department accounts for around 5\% of the Norwegian MHE. The pioneer on twin studies of mental health, Svenn Torgersen, was employed at the department in more than 30 years, and younger twin researchers (Røysamb and Czajkowski) joined the department later, which explains why most of the MHE research at this department is twin studies (some of these papers will be described later (28-33)). Much of the twin research and some other epidemiologic research take place in close collaboration with researchers at the NIPH. Highly productive MHE researchers are Nikolai Czajkowski, Espen Røysamb, Kjetil Sundet and Svenn Torgersen.

The Faculty of Psychology at the UiB also produces in the order of $5 \%$. The MHE research is spread on four of the faculty's five departments. Much of the faculty's MHE research is based on data from the big health studies (HUSK, HUNT and more) and the child- and adolescent study the Bergen Child Study (Barn i Bergen). Among the most productive MHE researchers at the faculty are Ståle Pallesen at the Department of Psychosocial Sciences and Inger 
Nordhus at the Department of Clinical Psychology, both with more than 20 hits.

Other groups or researchers. The remaining research on MHE, distributed across a number of institutions, is around $10 \%$. According to the result from the literature search, some highly productive MHE researchers are Lars Lien, Hedmark University College, Geir Selbæk, Head of Norwegian National Advisory Unit on Ageing and Health, Ingunn Skre, Institute of Psychology, University of Tromsø, Tore Wentzel-Larsen, RBUP South and East, and Lars Wichstrøm, Department of Psychology, NTNU.

\section{SOME PIONEERS AND KEY FIGURES IN NORWEGIAN MHE FROM THE NINETEEN EIGHTIES}

A few names deserve mentioning beside those already mentioned in the introduction and belonging to the old epoch. Odd Steffen Dalgard and Nils Johan Lavik (8) deserve credit not only for their early, but also for their later work. Arnulf Kolstad, retired professor from NTNU, was early out with his thesis on mental structures in children and adolescents (34) but has later worked more with social psychology and issues outside epidemiology. Tom Sørensen in 1983-84 conducted an epidemiological interview study in Lofoten (35) with a sample that was re-interviewed twice and later compared with a sample in Oslo. Alv A. Dahl established a group of MHE researchers mostly from Bergen and Trøndelag, using the data material on mental health from the HUNT2 in 1995-97 and other population based studies, like Hordaland Health Study (HUSK). Dahl and his former PhD students have published a large number of epidemiological studies based on HUNT, HUSK, and other data materials. Dahl is among the most frequently cited MHE researchers in Norway.

As generally recognized Ørnulf Ødegaard was the founder of Norwegian and a pioneer in international psychiatric epidemiology. Next to him the nestor in Norwegian MHE is Einar Kringlen, and Svenn Torgersen has also had a special role in early MHE. Their careers started well before 1990, but they have also been leading figures up until recently. Although working at different faculties/departments (Medicine and Psychology) of University of Oslo, they have been working closely together most of their careers.

Einar Kringlen was born in Høyanger, Sogn og Fjordane in 1931 and graduated in medicine at the University of Bergen in 1958. In 1961 he was employed at the Psychiatric Clinic at the University of Oslo as an assistant physician and from 1964 to 1967 as a Research Council funded fellow. He moved to Bergen in 1967, where he worked a few years at the university and Haukeland Hospital, then for two years as a professor in psychology at the University of Bergen, before he returned to Oslo. He was the Head of Department of Behavioural Sciences in Medicine in Oslo from 1977-83, then from 1983-2001 a professor in psychiatry and Head of Psychiatric Clinic at the UiO. In his first period at Psychiatric Clinic in Oslo, 196167, he founded the Norwegian Twin Registry, which at that time was among the largest in the world. It included Norwegian twins born 1901-1930, later expanded to the cohorts $1895-1945$, and later again expanded by others to 1960 . He used the twin registry for a number of important publications on schizophrenia, to some of which I will return. He was internationally recognized as a distinguished twin researcher on mental health shortly after publishing his work on schizophrenia in 1966 (14) and doctoral dissertation in 1967 (15). Together with Torgersen and Victoria Cramer he conducted an epidemiologic interview study of all the most common mental health and personality disorders except schizophrenia in Oslo and in Sogn og Fjordane county $(17,18,32)$.

Svenn Torgersen, born 1941 in Blaker, Akershus, graduated as a psychologist in 1968. He worked as a Fellow funded by the Research Council and as an assistant professor until being appointed Head of the Research Council's Center for Clinical Psychological Research at Department of Psychology, UiO in 1978. He was appointed professor in clinical psychology at the Department of Psychology, UiO in 1986. Like Kringlen, Torgersen used the twin registry to identify twins suffering from mental illness. He published his first important papers in 1979 (28) and 1983 (29) on anxiety disorders, but has later attracted even more attention for his studies on personality disorders $(31,32)$. He received the University of Oslo Research Award in 1999 in competition with approximately 3000 researchers at the university. Torgersen's twin research is not among the most methodically subtle, and like with much early twin research, the statistical power of his studies has not always permitted safe conclusions. His great merit has been his ability to bring new highly needed knowledge, especially on personality disorders, for which results on occurrence and genetic effects were for a long period scarce.

\section{A SAMPLE OF IMPORTANT PUBLICATIONS}

\section{Twin research, including some old studies}

The first twin study on schizophrenia in the world was published in 1928 (36), and by 1967 there were at least nine studies (16). These studies were partly small, however, and all were based on samples drawn from clinics. Einar Kringlen was in 1967 the first to publish results based on a population data material (15). For the first time one could trust that the results were not severely biased by sample selection, and soon this study was ranked as one of the four most important twin studies on schizophrenia till then, as for instance indicated by the choice of studies to a prominent metaanalysis (37). Identification data from the national twin registry for twins aged 35-64 years were linked with The Central Registry for Hospitalizing of Mentally Ill 
Persons. 342 pairs with one or two twins suffering from schizophrenia were identified. The results challenged earlier studies, showing lower concordance rates. The rates varied from $25 \%$ to $38 \%$ in monozygotic twins and $4-10 \%$ in dizygotic twins, depending on whether the diagnosis was taken from hospital records or personal examination by the author.

An example of early papers by Torgersen is his paper on comorbidity of depression and anxiety disorders (30). The relationship among major depression only, major depression with anxiety disorders, and anxiety disorders only was investigated in a twin sample ( $\mathrm{N}=177$ pairs). The evidence suggested that there are common familial (probably genetic) causal factors for major depression and mixed major depression-anxiety disorders, but not for those two disorders and pure anxiety disorders. Torgersen's most highly cited publication on twin studies was the first to report heritability estimates for the whole range of personality disorders, all recorded by interviews (31). Based on twin and patient registries, 92 monozygotic and 129 dizygotic twin pairs were examined. Since the twins were recruited from clinics, observed prevalence rates from a normal population study of more than 2,000 individuals were used in combination with data from the twin study to generate statistics assumed to be valid for a normal twin population. The best-fitting models showed a heritability of 0.60 for PDs generally, 0.37 for the eccentric (A) cluster, 0.60 for the emotional (B) cluster, and 0.62 for the fearful (C) cluster. The results did not show clear evidence of effect of environmental factors shared by the co-twins.

There has also been quantitative genetic research on psychological characteristics in Norwegian twins and families since the nineteen eighties outside Kringlen's and Torgersen's group, but most of it was on cognitive ability (38). There was also some twin and family research on mental health before the millennium, primarily at the Norwegian Institute of Public Health, but this was based on symptom scores from questionnaires and did not have the same impact (39). A new study of Norwegian twins born 1967-74 was started at the NIPH in 1992. In 1998 a follow-up was extended to twins born 1975-79 (40). The participants were invited to an interview study on mental health during the period 1999-2003. An important advantage of the study is the richness of the types of disorders examined in the study. All the most important DSM IV and ICD 10 diagnoses except schizophrenia - also the personality disorders - are included. Whereas traditional twin studies asked to what extent the variation of a characteristic is determined by genes, most modern twin studies also aims to answer the important question to what extent the covariation between two or more characteristics is determined by genes common to the characteristics (pleiotropy) and to what extent by common environmental factors. A large number of publications are based on the NIPH interview study, and the vast majority of them focus on genetic and environ- mental relatedness between disorders. For example Reichborn-Kjennerud et al. (20) reported results suggesting that social phobia and avoidant personality disorder are influenced by the same genes, but not much by the same environmental factors. An implication is that genes to a certain extent decide whether a person will have one of the disorders, but that only environmental factors determine which of the two disorders - social phobia or avoidant personality disorder - a genetically disposed person will have. Another recent study based on the same data material (21) showed that a highly heritable $(55 \%)$ general borderline PD factor common to the nine DSM-IV criteria for this diagnosis strongly influences all nine BPD criteria. Røysamb et al. showed that a high correlation between subjective well-being and self-perceived general health $(\mathrm{r}=0.50)$ primarily could be accounted for by common genes (33).

\section{A sample of other important epidemiological publications since the late nineties}

Molecular genetic studies are increasingly important in MHE. Vidar Steen et al. as early as 1997 in a highly cited study (26) examined the possible association between the dopamine D3 receptor gene and the risk of severe tardive dyskinesia (TD), a side effects of antipsychotic drugs in schizophrenic patients. Such an association was demonstrated. The authors concluded that the finding might improve the understanding of the pathophysiological mechanisms of TD and influence the design and choice of future anti-psychotic drugs.

The prevalence of depressive mood was examined in 12,000 Norwegian adolescents in the "Young in Norway" study (described later). Lars Wichstrøm in 1999 studied sex and age differences in depression (41). From the age of 14, girls scored 0.5 SD above boys in depressed mood, whereas no gender difference was found at age 12. An extended version of the gender intensification hypothesis was tested as an explanation for the gender difference. The results showed that the gender difference could be explained, in part, by increased developmental challenges for girls: pubertal development, dissatisfaction with weight and attainment of a mature female body, and increased importance of feminine sex role identification.

Based on data from Oslo and Sogn og Fjordane, Kringlen, Torgersen and Cramer in 2001 and 2006 estimated prevalences for all the most important types of mental disorders except personality disorders and schizophrenia $(17,18)$. Taking the estimates from Oslo and Sogn og Fjordane together, the results are mostly typical of findings from high-quality studies in Western countries outside Norway $(42,43)$. Interestingly, however, the risk of any mental disorder during a 12 month period was as high as $32.8 \%$ in Oslo, as compared to $16.5 \%$ in Sogn og Fjordane. The corresponding figures for lifetime prevalences were $52.4 \%$ and $30.9 \%$.

According to the authors, Svenn Torgersen et al., the Oslo and Sogn og Fjordane study was the first to 
publish prevalence data on a full set of personality disorders based on a large representative sample of the common population (32). In a highly cited paper from 2001 avoidant personality disorder was reported to be the most common, with a prevalence of $5 \%$, whereas $13.4 \%$ was observed to have at least one personality disorder.

A paper from UiB by Ingvar Bjelland et al. from 2003, "Folate, Vitamin $\mathrm{B}_{12}$, Homocysteine, and the MTHFR $677 \mathrm{C} \rightarrow \mathrm{T}$ Polymorphism in Anxiety and Depression. The Hordaland Homocysteine Study" (24) is also among the most frequently cited in Norwegian MHE. Symptoms of anxiety and depression were reported by 5948 subjects. Multivariate analyses showed that plasma homocysteine level and the T/T methylenetetrahydrofolate reductase genotype were positively associated with depression, but not with anxiety.

Together with Sophie Fosså and others, Alv A. Dahl has been working with the relationship between cancer and loss of well-being and mental health. In a study of 1408 long-time survivors of testicular cancer (19), the results showed a relative risk for anxiety disorders of 1.49 in the cancer survivors compared to a norm sample. No increased risk was found for depression. The risk of anxiety disorder in the cancer survivors was associated with young age, peripheral neuropathy, economic problems, alcohol problems, sexual problems, relapse anxiety, and having been treated for mental problems.

In a paper from 2007 (25) based on data from the longitudinal Bergen Child Study, Einar Heiervang et al. reported a prevalence of $6.9 \%$ for any ICD-10 mental disorder in children 8-10 years old. The study includes information both from parents and teachers. The prevalence estimates for separate groups of disorders were $3.4 \%$ for emotional disorders, $3.1 \%$ for behavior disorders, and 1.4\% for ADHD/hyperkinetic disorders. Learning difficulties, poverty, and "nontraditional family" (mainly single parent or parent with a new partner) were risk factors for all types of disorders.

A study by the late Dag Neckelman et al. (44), based on data from the population-based HUNT1 and HUNT2 samples, prospectively examined the relationship between insomnia and the development of anxiety disorders and depression. Self-reported symptoms of anxiety disorders and depression in HUNT2 were analyzed adjusting for various covariates. Anxiety in HUNT2 was significantly associated with insomnia in HUNT1 only (OR 1.6), with insomnia in HUNT2 only (OR 3.4), and with insomnia in both surveys (OR 4.9). Depression in HUNT2 was only significantly associated with insomnia in HUNT2 (OR 1.8). The results are consistent with insomnia being a risk factor for the development of anxiety disorders, but not for depression.

Another sleep study using HUNT data by Børge Sivertsen et al. used only the HUNT2 sample crosssectionally, but extended the outcome measures from anxiety and depression to a number of mental and physical outcomes (45). The results demonstrate that insomnia symptoms are associated with a range of different conditions and suggest that the independent contribution of insomnia is strongest on conditions characterized by some level of psychological or psychosomatic properties.

Dag Aarsland and his group at Stavanger University Hospital are among the internationally leading on research on Parkinson's disease, which is not a subject to MHE as defined here. Nevertheless this group has also produced important MHE research. An example is a highly cited publication from 2007 of neuropsychiatric symptoms in 557 demented patients with Parkinson (27). The most common symptoms were depression (58\%), apathy (54\%), anxiety (49\%) and hallucinations $(44 \%)$. The authors conclude that such symptoms are common in patients with dementia associated with Parkinson, and that the profile of these symptoms differs from that of other types of dementia.

A publication from 2011 in JAMA by Christine Roth et al. (22), based on the MoBa study, showed that maternal use of folic acid supplements in early pregnancy was associated with a reduced risk of severe language delay in three year old children. This is one of a number of studies from MoBa showing a protective effect of folic acid during pregnancy on later childhood development.

Ole Andreassen et al. in a new consortium study from 2015 used three enormous samples ranging from 17,000 to 27,000 subjects (13). They were able to show genetic pleiotropy (the same genes coding for more than one phenotype) for multiple sclerosis and schizophrenia caused by 21 independent genetic loci. They did not find evidence for such pleiotropy for multiple sclerosis and bipolar disorder.

\section{IMPORTANT DATA MATERIALS}

As with Norwegian epidemiology in general, epidemiology on mental health has, or has had, some comparative advantages. Until recently the Norwegian population was quite stable, with moderate immigration or emigration, and the rate of moving was rather low. The citizens have a relatively high confidence in the societal authorities, and the willingness to participate in epidemiologic studies has been relatively high. This is particularly important for studies on sensitive issues like mental health. We have for a long time had a number of excellent health population studies, although with varying amounts of mental health information. Equally valuable are the health- and demographic registries, which can be linked with the epidemiological data materials.

The regional health studies were run by the National Health Screening Service (NHSS), which existed until 2000. Many of the studies include almost the full adult population of single counties. At first the NHSS screened primarily for tuberculosis, later it shifted to other health problems, especially cardiovascular ill- 
ness. From the nineteen eighties a few (and after some years an increasing amount of) questions on mental health were also included in some of the studies. At least two of these studies are still ongoing. The Tromsø Study started 1974 and The Nord-Trøndelag Health Study (HUNT) in 1984, both with several follow-ups. There is almost no information on mental health in the first three Tromsø Studies, but in Tromsø 4-6 there are items on symptoms of anxiety and depression. There were a few questions on general mental health and psychological well-being in HUNT1. HUNT2 and HUNT3 included questions on well-being, self-esteem, and symptoms of anxiety and depression. From HUNT2 on the HUNT studies have also included studies of the adolescent population from 13 to 19 years (YoungHUNT), with several questions on symptoms of anxiety and depression, behavior problems and factors relevant to mental health. Both Tromsø and HUNT have data on alcohol consumption, from the start only a few questions, in the newer studies somewhat more detailed. Both data materials have strengths like high participation rates and richness of available exposure data. HUNT has invited the full population from age 20 years each time, since HUNT2 from age 13 years. That implies that the material is well suited for family analyses, such that for instance self-reported mental health in adolescents can be analyzed together with self-reported data from the parents. The family data also permit various types of genetic analyses.

Besides HUNT and the Tromsø Study, data from some of the other regional studies, like HUBRO (46) and HUSK (47), have also been used and can still be used for MHE research. One data base, the CONOR (48), consists of data from many of the regional studies from around 200,000 subjects. Among the variables are eight scores tapping symptoms of anxiety and depression together with a lot of somatic health data and biological samples.

\section{NOVA-studies of adolescents}

Even if NOVA's research profile is social rather than health oriented, the institute has contributed considerably to MHE and has been running large studies with valuable MHE data. The project "Young in Norway" was started in 1992 (49). Approximately 12,000 adolescents aged 14-19 years spent two school hours completing a questionnaire. Because the data collection took place at school the participation rate reached 97\%. Parts of the sample was followed-up three times during the next ten years. A new study "Young in Norway 2002" with the same sample size was started in 2002.

NOVA is now, together with seven regional centers for drug abuse (KoRus), conducting the ongoing study Ungdata (Young-data - www.ungdata.no). Each municipality in Norway is locally responsible for running a yearly data collection at schools from pupils 13-19 years. The questionnaire items are partly common to all municipalities, partly specific and chosen by each municipality. The study has been going on since 2010 and so far 190,752 out of 233,709 invited adolescents have participated (participation rate $82 \%$ ). Main themes in Young-data have been categorized as 1) personal development (identity, self-esteem), 2) sociability/ social network, 3) leisure time, 4) parents (parenting, parents' life style), 5) attitudes to the society, politics, values, 6) problems (drug abuse, eating problems, behavior problems, suicidal behavior, anxiety and depression) and 7) school, education, career (50). Themes for the common part of the Ungdata questionnaires are "relatives and friends", "leisure time", tobacco and drugs", "school and future", "health and well-being", and "risk behavior and violence". Even if the questionnaire items on mental health and behavior problems are rather crude and not very detailed in these data sets, they will probably be priceless for Norwegian epidemiological research on adolescents in the years to come.

\section{The Oslo and Sogn og Fjordane epidemiology studies}

The aforementioned interview studies by Kringlen, Torgersen and Victoria Cramer in Oslo (17) and in Sogn og Fjordane county (18) during the period 199499 include all the most usual mental health and personality disorders except schizophrenia. The sample size, a little over 3000 in both studies combined, is not enormous, but the participation rate is high and the structured interviews used are considered state of the art. The study is by far the most important national source of knowledge of the occurrence of mental disorders.

\section{Barn i Bergen (Bergen Child Study)}

In this longitudinal study at the RKBU West, Uni Research, all 9430 children born in Bergen in 19931995 were invited. The children were followed-up three times from early school age (8-10 years) until adolescence. From wave 1 there are valid data on the instrument Strength and Difficulties Questionnaire (51) completed by teachers for 9155 children and by parents for 6297 children. 1446 screening positive children with parents were invited to a psychiatric interview and 645 accepted, whereas 732 screening negative were invited and 364 accepted. Strengths of this study are the high participation rate from the start, the large sample, the use of a full, established psychometric instrument, and data reported by both parents, teachers, and the children themselves.

\section{The Norwegian Mother and Child Study (MoBa)}

This study ascertains data from 114,000 children and their mothers and fathers (52). Pregnant women were invited to the study when appointment was made to the first routine ultrasound examination at 17 th week of pregnancy. Questionnaires typically 15 pages long were completed by mothers at pregnancy week 17, 22 and 30 and when the children were six months, 18 
months, three years, five years, seven years, and eight years old. New questionnaires are planned for both mothers and children themselves when the children are 13 years. Fathers complete two questionnaires.

In the first questionnaire to mothers there are approximately two pages with questions pertaining to the mothers' mental health, well-being and alcohol use, in all later questionnaires except two there are typically three pages with items on these issues. The questionnaire completed when the child is 6 months contains a few questions about the child's emotional and behavioral development, whereas in all but one later questionnaires in the order of $1 / 3$ to $2 / 3$ of the total space is used on questions on the child's emotional, cognitive, lingual, and behavioral development and mental health.

These data can be linked to other sources, such as the Medical Birth Registry as well as outcome data from health registries like the Norwegian Patient Registry. The combined data make it possible to study causal factors back to the pregnancy period on the child's life-long health. The data are also suitable for studying maternal and paternal health. The participation rate is $40.6 \%$ and there is also a substantial dropout, implying that the data material is less suited for assessing occurrence than effects of risk factors. Another limitation is the use of abbreviated psychometric instruments. Fortunately the correspondence between the scores from the original instruments and the shortform versions has been estimated for most of the instruments, and the correlations are generally high. Rather crude measures on mental health imply quite low discriminant validity for the separate types of mental health problems and for specific mental disorders. Advantages are the large sample, information from both parents and (soon to come) from the children, and frequently obtained information through a long time span, finally through the whole life. The MoBa material is already very attractive to MHE researchers. So far 17 out of $33 \mathrm{MoBa}$ dissertations and around one third of 325 publications based on $\mathrm{MoBa}$ data can be categorized as MHE.

\section{Health registries and other registry data}

Due to reduced willingness to participate in population studies in Western societies, more and more MHE research is likely to be based on registry data, or perhaps on questionnaire data in combination with registry data, a trend that has already started. In particular self-report data from years back, when the participation rate was high, can be successfully linked with new registry data. The vast majority of the readers of Norsk Epidemiologi are aware of the valuable highquality Norwegian registries, so I will only mention a few. Both health registries, like the Norwegian Patient Registry (53), with individual diagnostic data from Norwegian hospitals back to 2009, and KUHR, with diagnostic data from Norwegian general practitioners, will be very important to future epidemiological research. The same is the case for demographic registry information and information about family identity. The challenge ahead will be for the authorities to make these data sources available to research by adapting a good and flexible personal security legislation.

\section{CONCLUSION}

Norwegian epidemiological research on mental health has traditions back to the 1930s, but until around 1990 only counted a few researchers, all medical doctors. A new appreciation of the importance of both epidemiology and mental health in general arose from the 1980s. This resulted in new funding sources and research positions in the field of mental health, and mental health epidemiology in particular. A corresponding increase in publication is seen from 1990, and there is an even stronger increase from 2000. The estimated proportions of publications among institutions are far from exact. One of several short-cuts in the estimation procedure is the lack of differentiating between first- and co-authorships. This favors older (and thereby male) researchers, whose rate of coauthorships is usually higher than among young researchers. The choices of described MHE papers are largely based on citation statistics, which also favor old papers, since it takes some time for a paper to get highly cited. Still I think the reported statistics gives an approximately correct picture of a quickly expanding national MHE research activity, spread on several institutions with a large number of researchers.

\section{ACKNOWLEGEMENT}

I am grateful to Leif Edvard Aarø, Ole Andreassen, Ottar Bjerkeseth, Per Magnus, and Ulrik Malt for their advise.

\section{REFERENCES}

1. Dalgard OS. Psykiatrisk epidemiologi i Norge - et historisk tilbakeblikk. Norsk Epidemiologi 2002; 12: 16372 .

2. Holst F. On the Statistics of the Insane, Blind, Deaf and Dumb, and Lepers, of Norway. Translated from Danish by A.S. Oliver Massy, Esq. Royal Stat Soc London J 1852; 15: 250-6.

3. Ødegaard Ø. Emigration and insanity. Acta Psychiatr Neurol Scand 1932; Suppl 4.

4. Noreik K, Ødegaard Ø. Psychosis in Norwegians with background of higher education. Br J Psychiatry 1966; 112: $43-55$.

5. Ødegaard Ø. The incidence of psychosis in various occupations. Int J Soc Psychiatry 1956; 2: 85-104. 
6. Bremer J. Social psychiatric investigation of a small community in Northern Norway. Acta Psychiatr Scand 1951, Suppl 62.

7. Lavik NJ. Ungdoms mentale helse. Oslo: Universitetsforlaget, 1976.

8. Dalgard OS, Tambs K. Urban environment and mental health. A longitudinal study. Br J Psychiatry 1997; 171: $530-6$.

9. Sandanger I. Occurrence of psychiatric disorders - an epidemiological study, conceptual, methodological and empirical issues (doctoral dissertation). Oslo: University of Oslo, 1999.

10. Dalgard OS, Døhlie E, Ystgaard M (ed). Sosialt nettverk, helse og samfunn. Oslo: Universitetsforlaget, 1995.

11. Karevold E, Røysamb E, Ystrøm E, Mathiesen KS. Predictors and pathways from infancy to symptoms of anxiety and depression in early adolescence. Dev Psychol 2009; 45: 1051-60.

12. Annual report 2014. Oslo, Norway: Norwegian Centre for Violence and Traumatic Stress Studies, 2015.

13. Andreassen OA, Harbo HF, Wang Y, Thompson WK, Schork AJ, Mattingsdal M, et al. Genetic pleiotropy between multiple sclerosis and schizophrenia but not bipolar disorder: differential involvement of immunerelated gene loci. Mol Psychiatry 2015; 20 :207-14.

14. Kringlen E. Schizophreni in twins. An epidemiological-clinical study. Psychiatry 1966; 29: 172-84.

15. Kringlen E. Heredity and Environment in the Functional Psychoses. An epidemiological-Clinical Twin Study. London, UK: Heineman, 1967.

16. Kringlen E. An epidemiological-clinical twin study on schizophrenia. J Psychiatr Res 1968; 6 suppl 1: 49-63.

17. Kringlen E, Torgersen S, Cramer V. A Norwegian psychiatric epidemiological study. Am J Psychiatry 2001; 158: $1091-8$.

18. Kringlen E, Torgersen S, Cramer V. Mental illness in a rural area: a Norwegian psychiatric epidemiological study. Soc Psychiatry Psychiatr Epidemiol 2006; 41: 713-9.

19. Dahl AA, Haaland CF, Mykletun A, Bremnes R, Dahl C, Klepp O, Wist E, Fosså SD. Study of anxiety disorder and depression in long-term survivors of testicular cancer. J Clin Oncol 2005; 23: 2389-95.

20. Reichborn-Kjennerud, Czaikowski N, Torgersen S, Neale MC, Ørstavik RE, Tambs K, Kendler KS. The relationship between avoidant personality disorder and social phobia: A population-based twin study. Am J Psychiatry 2007; 164: 1722-8.

21. Reichborn-Kjennerud T, Ystrom E, Neale MC, Aggen SH, Mazzeo SE, Knudsen GP, Tambs K, Czajkowski NO, Kendler KS. Structure of genetic and environmental risk factors for symptoms of DSM-IV borderline personality disorder. JAMA Psychiatry 2013; 20: 1206-14.

22. Roth C, Magnus P, Schjølberg S, Stoltenberg C, Surén P, McKeague IW, Davey-Smith G, ReichbornKjennerud T, Susser E. Folic acid supplements in pregnancy and severe language delay in children. JAMA 2011; 306: 1566-1573.

23. Bjerkeset O, Romundstad PI, Evans J, Gunnell D. Association of adult body mass index and height with anxiety, depression, and suicide in the general population. The HUNT study. Am J Epidemiol 2008; 167: 193-202.

24. Bjelland I, Tell GS, Vollset SE, Refsum H, Ueland PM. Folate, Vitamin $\mathrm{B}_{12}$, Homocysteine, and the MTHFR $677 C \rightarrow$ Polymorphism in anxiety and depression. The Hordaland Homocysteine Study. Arch Gen Psychiatry 2003; 60: 618-26.

25. Heiervang E, Stormark KM, Lundervold AJ, Heimann M, Goodman R, Posserud M-B, et al. Psychiatric disorders in Norwegian 8- to 10-year-olds: An epidemiological survey of prevalence, risk factors, and service use. J Am Acad Child Adolesc Psychiatry 2007; 46: 438-47.

26. Steen VM, Løvlie R, MacEwan T, McCreadie RG. Dopamine D3-receptor gene variant and susceptibility to tardive dyskinesia in schizophrenic patients. Molecular Psychiatry 1997; 2: 139-45.

27. Aarsland D, Brønnick K, Ehrt U, De Deyn PP, Tekin S, Emre M, Cummings JL. Neuropsychiatric symptoms in patients with Parkinson's disease and dementia: frequency, profile and associated care giver stress. $J$ Neurol Neurosurg Psychiatry 2007; 78: 36-42.

28. Torgersen S. The nature and origin of common phobic fears. Br J Psychiatry 1979; 134: 343-51.

29. Torgersen S. Genetic factors in anxiety disorders. Arch Gen Psychiatry 1983; 40: 1085-9.

30. Torgersen S. Comorbidity of major depression and anxiety disorders in twin pairs. Am J Psychiatry 1990; 147: 1199-202.

31. Torgersen S, Lygren S, Øien PA, Skre I, Onstad S, Edvardsen J, Tambs K, Kringlen E. A twin study of personality disorders. Compr Psychiatry 2000; 41: 416-25.

32. Torgersen S, Kringlen E, Cramer V. The prevalence of personality disorders in a community sample. Arch Gen Psychiatry 2001; 58: 590-6.

33. Røysamb E, Tambs K, Reichborn-Kjennerud T, Neale MC, Harris JR. Happiness and health: Environmental and genetic contributions to the relationship between subjective well-being, perceived health, and somatic illness. J Pers Soc Psychol 2003; 85: 1136-46.

34. Kolstad A. Til diskusjon om sammenhengen mellom sosiale forhold og psykiske strukturer. En epidemiologisk undersøkelse blant barn og unge (doctoral dissertation). Aalborg, Denmark: Universitetet i Aalborg, 1983. 
35. Sørensen T. Mental helse i Nordkyst. Nordland Fylkeskommune, Fylkeshelsesjefen, 1987.

36. Luxenburger H. Vorläufiger bericht über psychiatrische Serienuntersuchungen an zwillingen. Z Gesamt Neurol Psychiat 1928; 116: 297-326.

37. Sullivan PF, Kendler KS, Neale MC. Schizophrenia is a complex trait. Evidence from a meta-analysis of twin studies. Arch Gen Psychiatry 2003; 60: 1187-92.

38. Tambs K, Sundet JM, Magnus P, Berg K. Genetic and environmental contributions to the covariance between occupational status, educational attainment, and intelligence: A study of twins. Behav Genet 1989; 19: 20922.

39. Tambs K, Moum T. Low genetic effect and age specific family effect for symptoms of anxiety and depression in nuclear families, halfsibs and twins. $J$ Affect Disord 1993; 27: 183-95.

40. Harris JR, Magnus P Tambs K. The Norwegian Institute of Public Health Twin Panel: A description of the sample and program of research. Twin Res 2002; 5: 415-23.

41. Wichstrøm L. The emergence of gender difference in depressed mood during adolescence: The role of intensified gender socialization. Dev Psychol 1999; 35: 232-45.

42. Kessler RC, Berglund P, Demler O, Jin R, Merikangas KR, Walters EE. Lifetime prevalence and age-of-onset distributions of DSM-IV disorders in the National Comorbidity Survey Replication. Arch Gen Psychiatry 2005; 62: 593-602.

43. Bij1 RV, Ravelli A, van Zessen G. Prevalence of psychiatric disorder in the general population: results from the Netherlands Mental Health Survey and Incidence Study (NEMESIS). Soc Psychiatry Psychiatr Epidemiol 1998; 33: 587-95.

44. Neckelmann D, Mykletun A, Dahl AA. Chronic insomnia as a risk factor for developing anxiety and depression. Sleep 2007; 7: 873-80.

45. Sivertsen B, Krokstad S, Øverland S, Mykletun A. The epidemiology of insomnia: Associations with physical and mental health. The HUNT-2 study. J Psychosom Res 2009; 67: 109-16.

46. Søgaard AJ, Selmer R, Bjertness E, Thelle D. The Oslo Health Study: The impact of self-selection in a large, population-based survey. Int J Equity Health 2004; 3: 3.

47. Øverland S, Glozier N, Mæland JG, Aarø LE, Mykletun A, Employment status and perceived health in the Hordaland Health Study (HUSK). BMC Public Health 2006; 6: 219.

48. Næss Ø, Søgaard AJ, Arnesen E, Beckstrøm AC, Bjertness E, Engeland A, et al. Cohort Profile: Cohort of Norway (CONOR) Int J Epidemiol; 37: 481-5.

49. Wichstrøm L. Ung i Norge. Norsk Epidemiologi 2002; 12: 231-237.

50. Robertson IE. Ungdata - Ungdomsundersøkelser med kommunal forankring og nasjonal rekkevidde. Stavanger: Rusfag nr. 1, 2011.

51. Goodman R. The Strengths and Difficulties Questionnaire: A Research Note. J Child Psychol Psychiatry 1997; 38: 581-6.

52. Magnus P, Irgens LM, Haug K, Nystad W, Skjærven R, Stoltenberg C and The Moba Study Group Cohort profile. The Norwegian Mother and Child Cohort Study (MoBa). Int J Epidemiol 2006; 35: 1146-50.

53. Bakken IJ, Surén P, Håberg SE, Cappelen I, Stoltenberg C. Norsk pasientregister - en viktig kilde for forskning. Tidsskr Nor Legeforen 2014; 134: 12.

\section{APPENDIX 1. Web OF SCIENCE LITERATURE SEARCH}

In order to check the specificity of the 2794 hits, I inspected a $10 \%$ sample of them, stratified by publication year but otherwise randomly drawn. Main criterion for being judged as a relevant study was that the outcome variable - in a regular epidemiological study or a quantitative genetic study - was a measure of mental health, emotional well-being or drug/alcohol abuse. In correspondence with the choice of the search terms, dementia, sleeping problems, pain, somatic health, or use of medication as a proxy for a mental disorder did not count as a relevant outcome variable (not even when a mental health measure was included as a predictor, a choice that could be discussed). Research with the primary aim of examining or improving methods essential to MHE, like attrition studies or psychometric studies of screening instruments, was also classified as MHE. From the 280 inspected hits $(10 \%$ of 2794 hits), $58 \%$ (95\% CI $\pm 6 \%$ ) were judged to be relevant. From the $42 \%$ remaining hits, in the order of half are clearly irrelevant, the remaining touch MHE issues. In order to test the sensitivity of the search, I selected my own publications (with which I hope to be reasonably familiar) which I judged to be relevant and checked whether they were included in the search result. Seventy seven percent $(95 \% \mathrm{CI} \pm 9 \%)$ were retrieved. Judged from these values the figure includes some more irrelevant results than it leave out relevant results, implying a moderately inflated number of publications. On the other hand the criteria chosen for being counted as MHE are rather strict. 


\section{Criteria for literature search:}

The search does not intend to include studies with the following outcome variable:

Dementia, sleeping problems, pain, somatic health problems, use of medicaments as a proxy for mental disorders.

Search text: TOPIC: ((epidemiology or epidemiological or "risk factor" or causal or prevalence or incidence or genetic or twin or molecular or DNA) and (mental or psychiatric or anxiety or depression or ptsd or "post traumatic" or OCD or "obsessive compulsive" or schizophrenia or psychosis or psychotic or bipolar or "internalizing disorder" or "personality disorder" or "externalizing disorder" or ADHD or "conduct disorder" or "behavior problems" or "behaviour problems" or "drug use" or "drug abuse" or "drug dependence" or addiction or "alcohol use" or "alcohol abuse" or "alcohol dependence" )) AND ADDRESS: (Norway)

The hits are refined to articles, reviews and letters and to the following research areas:

Psychiatry or psychology or pediatrics or neurosciences neurology or demography or geriatrics gerontology or health care sciences services or public environmental occupational health or genetics heredity or behavioral sciences

\section{APPendix 2. Procedures for estimating the Relative distribution Of MHE PUBLICATIONS ACROSS INSTITUTIONS}

As mentioned the literature search resulted in 2794 hits. There were on average 5.2 authors for each publication, in total 14,463 authorships by 7272 authors. 44 researchers had 20 or more publications $(10.5 \%$ of all the authorships), 155 researchers had 10 or more authorships (19.9\%). Almost exactly $2 / 3(67.5 \%)$ of the authors had only one of the authorships on the list, which adds up to $1 / 3(33.9 \%)$ of the authorships.

A quantification of the total research production is easy and can be done through the library system CRISTIN or simply by reading the annual reports. These sources of information do not distinguish well between various types of research, however, and are not well suited to quantify MHE research separately. Another possibility would be to register the addresses of the 7272 authors of the 2794 papers in the search result already described and to count their working addresses. I can think of no other way to carry out such a registration than by manual work, however, and that would require a little too much effort. Instead the registration was restricted to the 229 researchers with eight or more publications, which covers $24.4 \%$ of the publications. Assuming that the proportion of highly producing researchers does not vary too dramatically from institution to institution, this sampling would give a good indication of the relative contribution from each institution. 